\title{
Teachers' Perception, Experiences, and Challenges about Teens of Ages 12-14 Years who have Reported Online Digital Insecurity in Kenya
}

\author{
Daniel Oloo Ong'ong'a 1* (D)
}

${ }^{1}$ Institute of Communication Studies, Communication University of China, CHINA

*Corresponding Author: oloodaniel2@outlook.com

Citation: Ong'ong'a, D. O. (2021). Teachers' Perception, Experiences, and Challenges about Teens of Ages 12-14 Years who have Reported Online Digital Insecurity in Kenya. European Journal of Interactive Multimedia and Education, 2(1), e02102. https://doi.org/10.30935/ejimed/9360

\begin{abstract}
This study explores teachers' perceptions, experiences, and challenges on teens ages 12-14 years old who have reported online insecurity issues in Kenya. The study recognizes that teachers have increased pressure to teach learners digital skills and manage their online and offline lives. Although much of the online insecurity discourse is children centric, little is known about the teacher's experiences when tackling teen's online safety issues. Outside the minimal discussion, an inferential approach towards the demarcation of online insecurity is reached that is coined on the professed notion of internet safety. Data was generated using an in-depth interview with respective teachers, Guidance \& counseling, ICT teachers, and school principal. A total of twenty-three participants were recruited who qualified for the study inclusion criteria. A qualitative intrinsic case study was employed, and data analyzed thematically. The findings from the study revealed that teachers lack online safety competency skills to protect teens. Therefore, they depend on the very learners they are supposed to protect to teach them to navigate digital platforms. It is imperative to integrate online digital insecurity in the Kenya curriculum to develop workable frameworks to support teens who have encountered troubles on the internet. The study recommends effective digital literacy instruction intervention for teachers to support the children in the online space effectively. Additionally, in-depth research exploring parents' responses to online challenges while protecting children is a gap that needs to be filled.
\end{abstract}

Keywords: teachers, online digital insecurity, children, digital literacy, school

Received: 28 Jun. $2020 \bullet$ Accepted: 21 Sep. 2020

\section{INTRODUCTION}

Online digital insecurity occurs when a child or a young person encounters information and contents online, that makes them uncomfortable (Malby et al., 2015). There are little measures employed to protect them online. Therefore, online security is the steps taken to keep safe from dangers on the Internet (Kachwanya, Muthoni, \& Khamadi, 2018). Globally, online digital insecurity has become ubiquitous, mainly due to the increase in Internet penetration that has connected the globe. The global connectivity of the Internet as a medium bridge the cultural gaps and fosters for different generations and communities to communicate. According to a report by the United Nations Children's Fund (UNICEF), the rise of the Internet has made it possible to increase insecurity in the corporate world and academic institutions (UNICEF, 2017). In light of this, the result of online danger is a global problem where children are also affected, with most sharing a lot of their personal information online hence falling prey to online predators.
Internet users in Kenya have steadily risen with the latest report indicating that 46.8 million Kenyans use the Internet. According to the Internet World Statistics (IWS), Internet penetration in Kenya is at $87.2 \%$, while Facebook, as a social media usage, stands at 7 million subscribers (IWS, 2020). The most popular social media platform used in Kenya is reported to be WhatsApp, while individuals of ages 35-45 age brackets utilize Facebook. Young people prefer using Instagram more frequently (Muigai \& Mantz, 2019). In 2013 the Kenya government initiative the process of the digitalization of the curriculum in schools in Kenya. The project Digital literacy program is implemented in all public schools in Kenya (ICT Authority, 2014). Other schools also took this initiative to foster 21st-century skills to the school-going children. There has been ever-increasing pressure for the teachers to teach digital skills and manage young people both online and offline. Byron (2008) argues that teachers are often afraid of teaching young people how to use the Internet for fear of misuse and misapplication. Schools in Kenya prohibit learners from owning or possessing mobile phone devices in schools because they have always complained that it makes them lose their school work concentration. 
The use of the Internet in Kenya has raised much concern among the teachers and other stakeholders (Asher, 2014). Digital safety issues in the country have raised concerns due to the lack of measures taken to control the contents that are accessed by the children. The teachers are the primary sources of digital safety information for young people in school. However, the teachers do not have adequate information about the issues and hence, negatively affect their ability to comprehend digital safety information (Kinyanjui, 2014). Byron (2008) postulates that young people feel that their teachers do not have adequate information regarding the digital safety issues and cannot provide them with the needed support. This perspective foregrounds the investigation of the present study. To this end, there is an increasing focus on studying the online safety of young people, and little is known about what teachers know and how they feel about being the guardians of the young people's online digital presence.

\section{LITERATURE REVIEW}

Several scholars have recently documented teachers' experiences on online safety concerns of learners, highlighting the inadequacy of skills as a significant challenge in protecting young people in the online platforms. According to the study done by Buchanan, Southgate and Smith (2019) found that teachers were aware of the issues that surround the digital safety of the children but that they had little knowledge of the positive potential of the digital platforms and how they could help children manage their online lives. Another relevant study was carried out by Govender and Skea (2015) on the e-safety issues related to teachers' awareness and knowledge in developing countries revealed that most of the teachers were not sufficiently knowledgeable about the online risks and their associate to online safety measures.

Waller's (2017) study indicated that the media convergence in multiple spheres had offered a unique challenge to teachers who require to tackle digital competencies and online safety issues. The scholar continues arguing that embedding Internet technologies in schools should focus on how different services are related to educational objectives. A related study by Hartikainen, Livari, and Kinnula (2019) on teens of ages 11-12 years old posits that every young person has their personal life online. Still, the teachers worry about their online safety. Hence, the need to engage teachers in designing and evaluating young people's own media culture values.

A study conducted by Kinyanjui (2014) in Kenya revealed that teachers resisted digital communication technologies in their schools because they lacked confidence and online digital-related skills. She farther points out that some of the school managers blocked introducing the online digital platforms in their school for fear of high maintenance costs and themselves lacking technological skills. Bose and Coccaro (2013) study disclosed that schools in Kenya do not have filter systems installed on the online digital platforms to block teens from accessing content that they wish. Surprisingly, the study exposed a low percentage of school teachers in Kenya who guided online safety in schools, even though Kenya was rated among the most advanced countries in terms of ICT penetration. The study recommends that for the teachers to offer preventive solutions and more suitable education for teens to fight online risks, they need to have the essential technical knowledge.

The study commissioned by UNICEF-2013 to comprehend how young people of ages 12-17 years in Kenya use digital technologies and the risks associated with them, revealed that teachers refer to Google to support in teaching relevant subjects in school. The report also points that young people use their phones surreptitiously during break time and hide them when their teachers watch (Gill, 2013). The studies reviewed relate to current research. They investigated teachers' experiences, challenges, and perceptions on issues of online digital safety of young people in different contexts. Therefore, this study seeks to advance the dialogue around online insecurity in the lenses of teachers' perceptions and their roles in safeguarding the young people in schools and offer suggestions to African countries on policy and legislative development. The following research questions are formulated for this study.

\section{RESEARCH QUESTIONS}

Q1. What are the experiences of teachers on teens who have reported online digital insecurity in Kenya?

Q2. What are the challenges face when teachers dealing with teens who have reported online digital insecurity in Kenya?

Q3. What are the perceptions of teachers on teens who have reported online digital insecurity in Kenya?

\section{METHOD}

The study adopted a qualitative approach. Qualitative research commits to the naturalistic interpretation of human experiences and points of view (Denzin \& Lincoln, 2005, p. 3). The approach emphasizes on subjective examination of individual experiences and narratives. Therefore, the study sought this approach to comprehend the holistic, dynamic, contextual, and complexity of different individuals and their expertise (Polit \& Beck, 2004, p. 249). The face-to-face discussion was done with this study's participants in one of the international schools in Kenya while they were in action. The method was feasible since it offered a chance to investigate the issue and collect data through a nonstandardized way of gathering data (Saunders, Lewis, \& Thornhill, 2009, p. 321).

A case study was used because it allowed for an in-depth investigation of a particular case (Creswell, 2014, p. 136). The case study was used as a method in this study. It offered the investigation an opportunity to study the contemporary phenomenon within its real-life context or natural setting. How people behave, think, and feel is only understood if we encounter their world and what they do. The intrinsic case study was also adopted to better understand the teacher's perceptions, experiences, and challenges on teen's online insecurity. Scholars such as Lodico, Spaulding, and Voegtle (2010, p. 162) advise that a case study is categorized as intrinsic when the investigation is to better understand a particular case.

The site and participants of this study were purposively sampled. The participants were purposively selected based on their importance, expertise, experience, and crucial role. One of the international schools in Nairobi was chosen because it is one of the schools with extensive technology usage among teachers. The school serves a diverse population of around 800 learners with mixed races. Teachers and learners have adequate access to online digital devices in the computer lab, and a rolling laptop cart. The learners use these tools to access the government and the school's digital literacy curriculum. Purposive sampling allows for the interaction with participants who are experts 
Table 1. Sampled participants

\begin{tabular}{cccc}
\hline & Female & Male & Total \\
\hline Class teachers & 10 & 9 & 19 \\
\hline Guidance \& counseling & 1 & 1 & 2 \\
\hline ICT teachers & 1 & & 1 \\
\hline Principle & 1 & & 1 \\
\hline Total & $\mathbf{1 3}$ & $\mathbf{1 0}$ & $\mathbf{2 3}$
\end{tabular}

Source (school-2016)

and experience in the field under investigation (Lindlof \& Taylor, 2002).

An inclusion criterion was used to delineate participants with a piece of vast information deemed rich. Then they were offered the chance to acquaint themselves with the main concerns of the study. It included the daily register event logs that class teachers of teens of ages 12-14 years, Guidance and counseling teachers keep when learners report online issues. This study included both female and male teachers working/tackling issues related to learners who have reported safety issues online, Guidance \& counseling, ICT teachers, and the school's principal. The teachers interviewed have a diploma in guiding and counseling, teacher education, management, and computer science; they also have many years of experience in their field, ranging from five to fifteen. The study recruited twenty-three participants who met the inclusion criteria-the participant for this study comprised thirteen females and ten males. Therefore, the participants recruited had an understanding of the phenomenon being investigated.

The study conducted twenty-three, in-depth interviews with the participants between August and October 2016. Scholars like Hargie and Tourish (2000, p. 98) advise that for compelling in-depth interviews they require few participants so that the study may reach saturation quickly. The time and the dates of the interviews were agreed upon and scheduled. The interviews were carried out in the school in a located private room for the visitors. The room offered a conducive environment to engage in a discussion. Since it was during the regular school hours, break and games time were agreed to conduct the interviews, which lasted for one hour each. Written consent was signed before the meetings. All the discussions were audio-recorded, and field notes were taken during the sessions. The recordings from the interviews were transcribed and then sent to the participants to sign a consent form.

Borrowing from Braun and Clarke (2013), the data were analyzed using six-phase thematic analysis techniques. The procedure involved familiarizing with the data, generating preliminary coding, and theme examination, revising the themes, naming and defining the topics, and finally reporting.

\section{RESULTS AND FINDINGS}

The results of this study show broad themes that existed which focused on the experience, perceptions, and challenges of teachers on teens' online digital insecurity. The following findings are discussed below with their subsequent sub-themes.
Teachers Experiences on Teens Online Digital Insecurity

Teens mobile phone devices ownership

The findings from this study revealed that teens own their phones. One of the participants felt the school should come up with measures to control the usage of phones by the teens;

It is currently challenging to deal with a situation concerning what phone that the parent buys the child. Although we have a time where children access their phones, the school should provide a more structured environment where children could be gagged. I tell you that sometimes we face things here that you cannot understand (Class Teacher-Male).

\section{Incorporating offline strategies to deal with online insecurities}

The participants felt that the school did not have any related online policies. They just adopted other strategies in the school:

To me, I think Mwalimu (English translation- Teacher). Here, I feel, let the school come up with a policy like the one we have. If you're sick, there's the office phone, which is usually fully recharged. As a teacher, if a child complains to you that he or she is ill, I take her to the office, call the parent, or take the child to the hospital and call the parent. That one is sorted. If it's technology, the tablets are there. The computer teacher is in control. Even if it is an Internet issue, we don't have huge groups going for computer lessons. It's a group of like 18 students in a class, controlled. A teacher will be able to walk around, seeing what is going on, "I told you to type this." These cheeky ones will type in something else, but you know the teacher is in control. I don't know the reason as to why we should now go to the extent of having a phone (ICT Teacher-Female).

\section{Innovation in dealing with online security in school}

The participants indicated that they have a guidance and counseling department to deal with indiscipline and safety issues in school. It was agreed that the school could not deal with online security among young people:

Usually, on Friday, a teacher invited an outsider to talk to them concerning this issue, a counseling teacher from another area who comes and tells them. Always every Friday, they're being spoken to. In that forum, they open up, guide them on whatever to do. Again, we, as teachers sometimes, talk to them. Not unless a teacher now you speak in case you get an area maybe where or a situation where you can talk. When you speak to them one by one, if you find out that perhaps one involves this kind of activity, you call him or her and then discuss with him because not everybody may be engaged in these issues (Guidance \& Counselling-Female).

\section{Integrating guidance and counseling in online security issues}

The participant felt that Guidance and counseling should address a more structured way of dealing with cybercrime in school:

We have life skills. That's why maybe the school has introduced this guidance and counseling program though sometimes it's tough to deal with this. Maybe at home, their culture is different than whatever they go through here. Perhaps the parent they take another line at home, but here in school, this may be what the school wants, sometimes it becomes challenging (Class Teacher-Male).

\section{School restriction to access to online digital platforms}

The following is noted by one of the participants to this study in regards to online digital devices in school;

It is illegal for them to come with those gadgets. In school, they know that. Nobody can get in with-Mobile phones. There's inspection before they get in for the borders. But we always find them with phones. There was a case I think in grade six, last year, or class six. For them, 
they will not carry to come and show information on the Internet or that. They will just bring because they want their friends to see they have a phone but not with anything. The big ones, we've never had such a case. Internet security in the school has been taken care of because we have computers. They have the tabs, but there's no Internet connection we provide sometimes. They get them from the teachers, go with them to class, then after everything they take them back (Principle-Female).

\section{Parents violation of school digital use rules}

Contrary to the above, one of the participants indicates that parents give mobile phones and other devices to teens to take them to school:

Periodically, I have witnessed a parent giving his daughter a mobile phone in the school, and it's difficult to stop it. Since the time is short for the conversation, you would find the parent informing you that let the child just have it, his/her sister who is abroad would want to speak to her, and I will pick it after. You will never see the parent till evening or when the school closes (Class Teacher-Female).

\section{Teachers Perceptions of Teens Online Digital Insecurity}

\section{Teens use of online digital devices}

Furthermore, the study revealed that when teens use their online digital devices, they may not only be texting and communicating with their friends but also accessing and exploring other sites;

Not the text messages but may be accessing the Internet, maybe SMS being directed by another person. Sometimes I understand they involve themselves in those activities on the Internet. Most of Grade seven and Grade eight, when they're left alone, the main aim or whatever they do with phones is to explore, more so with the Internet. That one I know they do (Class Teacher-Female).

\section{Teachers online mediation}

Experience from one of the participants demonstrates how a teen downloaded information from the Internet for fun:

My son had downloaded an app. These children are tricky. At times they will ask you for your phone. I'm also a mother to a teenager now, an adolescent, and at times they will want to have their phone, and they will tell you what they want to download. He's a fan of football. He will tell you he wants to see the players and all that. If maybe I'm not cautious, he might end up downloading some things that will not be good to him. I have to make sure that after he's through with the phone, I have to go and check what he was doing with it, specifically the messages and the sites (ICT Teacher-Female).

\section{Accidental exposure to indecent contents}

From the interviews, the participants argued that some of the parents forget to log out from pornography sites in their smartphones, hence exposing their teens to indecent images, pictures, and videos.

Here in this school, I've only experienced one, but they're a lot in my former school. There was an issue about pornography. Children getting access to the nude, and even at some point, there's a girl who made fun and said, as they were praying for food, she said that she prays very hard that all the girls in daddy's phone can be given clothes because the girls she sees on daddy's phone have no clothes (Class Teacher-Female).

\section{Teens knowledge of indecent habits}

Additionally, one of the participants had a divergent view concerning the accidental exposer of pornographic material:

The problem that I face as a class teacher is that the children that we are dealing with are very much exposed. Sometimes, it takes you a long period to learn that a specific child has been engaging in the indecent act. When you are harsh to a particular student, the accurate picture will come out. For instance, as a class teacher, you have to talk to these pupils regularly. I found out that the pupil started touching others appropriately during PE time. I followed this matter, only coming to realize from the boy later that he watched it from the video on his father's laptop (Class Teacher-Male).

\section{Teens online survival skills}

One of the participants alluded that the teens access obscene information because they have no guidance:

My colleague, the way she has put it, deals with discipline when they reach this adolescent stage. For these two years now, I have been working here as a boarding master. I can say yeah, there is an erosion of culture somehow. When they come home, they come with some ideas that you cannot expect a kid to know in that bracket of 12 to 14 They also ask you some questions that some time is tough to answer them. They ask you questions concerning even these movies which are sometimes not supposed to be watched by teenagers. They also tell you, because at home they have phones and nobody supervises them. They are indeed accessing these things from the Internet. After watching, after going through, they ask you some questions. As a teacher, sometimes you try to hide, you tell them this one is not right. The previous school where I came from, I had one case whereby a girl and a boy were in WhatsApp, and they were sending their pictures almost naked to one another (Class Teacher-Female).

\section{Exposure to fraudulent online activities}

The participants commented that teens are exposed to fraudulent activities online:

Last year, there is this case I was handling concerning a particular boy in my class; he had used his mother's visa card to purchase some items via the Internet. The boy had seen some shoes, and he wanted them, so, since he knew the password to the mom's visa card, he logged in and purchased the shoe. The funny thing is that until today the shoes were never delivered. The mom was furious with him after realizing about six months when she was cross-checking her bank statements. She saw some money transacted, which was suspicious of When she went to the bank, she was advised that her card had been used to buy some goods online, sometimes back at midnight (Class Teacher-Female).

\section{Puberty is the most challenging stage in teens}

The challenges the teachers face in dealing with the young people undergoing puberty is getting to know what the teens are doing online;

The challenge is when they start the puberty stage. It usually becomes a challenge. In most cases, that is the time they start realizing themselves. They want to explore. They want just to be felt, so it becomes a problem because balancing the academics and what they are going through is usually a challenge (Guidance \& CounsellingFemale).

\section{Teachers Challenges on Teens Online Digital Insecurity}

\section{Online cyberbully as a challenge to teachers}

Concerning the cyberbully, one of the participants indicated a need for essential skills and knowledge of dealing with problems that young people face online. One of the participants had this to say;

You know the problem we have is the management of the Internet as a resource. Imagine I do not have the necessary skills to find out if a child has been abused online. I will only know if he/she reports the same to me. I think we should go back to school or training on the emergence of such things (Guidance \& Counselling-Female). 


\section{Mistrust from teens towards teachers}

Although teachers are entitled to safeguard the safety of teens while at school, both physical and online, young people tend not to trust their teachers;

Yeah. I think it is the only case we've ever had, the one the principal was talking about though these were not the mature ones. The case was in class five, whereby there's a boy of eleven years old who got access to pornography. There was a kind of networking, and they communicated even at home. They would also text another which site to understand what. Unfortunately, one was caught by the mother. When he was asked where he got these entire, he said it was another boy in the same class who introduced him. You can imagine it had to be sorted, and we got the information. These children have a lot that they are experiencing but cannot reveal to anyone; we learn from others who report such cases (Guidance \& Counselling- male).

\section{Inadequacy of online safety policy}

One of the participants argued that the country currently does not have an online safety issues policy regarding schools:

In Kenya, I have not seen any policy regarding children's safety while interacting with the Internet. I hope your research will be of great help to this. The best option is to create awareness for both children and parents on the children's safety issues online. For instance, when a child finishes grade 8, you will see the first thing they demand from their parents is a phone and get into funny groups, they end up sharing pornographic material, telling you this is real (PrincipleFemale).

\section{Endangering young people through hands-off strategy}

One of the participants indicated that letting young people exposed to online insecurities is endangering their lives:

I think being a Christian school, we try to build the morals. Let's use the example of what we saw at that time. Beating this child might no help. Exposing the child might even bring more harm. What happened with the class teacher, the person who found or got the information has to follow a particular channel, has to go to teacher Samuel or maybe come to me so it's not exposed to everyone because not all of us will take it. It might even interfere with the child's esteem. From there, we discuss and involve the parent because, in most cases, these thing don't happen in school. We have to make the parent aware and guide the parents on how to go about it because if you are harsh, this is an adolescent. What will they do? They will rebel, understand? We try to instill a good part of it through discussion (Guidance \& Counselling-Female)

\section{Insufficiency of online safety issues in the curriculum}

One of the participants felt that the curriculum does not provide online safety issues regarding its technology utilization. Free access to the Internet exposes young people to online safety concerns:

Before the government comes up with that policy of children having phones in school, can we have specific phones with specific information of a particular age group. Like the way we buy textbooks. There's the information that a grade one should know should have from grade one books. The farthest can go to grade two. There's what that child can access through the phone. Can we have, that also if this child takes another child's phone, will still get the information that iseven things like theft cases and all that will be catered for. Can the government in the syllabus? Now they are talking about technology. Can the government develop books like the Lifeskills they have in the curriculum, whatever we have in the syllabus? Can it be included? Is it possible for ICT and use of ICT to be included in the program to know the dos and don'ts of that? Free access to the Internet has now made this issue of indiscipline in school where the boy/girl relationship is real (Principle-Female).

\section{DISCUSSIONS}

This study's findings revealed that teens own their phones given to them by their parents, relatives, and friends. These devices are used to text and communicate with their friends while exploring the Internet. Therefore, these findings are consistent with (Asher 2014; Byron, 2008; Gill, 2013), who confirms that young people in Kenya own phones and use them to stay in touch with their friends and families. This study's findings were contrary to Lee (2018) and Cunha, van Kruistum, and van Oers (2016) that social media positively benefits young people.

Besides, the findings also exposed that teachers felt that they needed to check and mediate the young people's online activities. In this light, these findings are partly similar to Buchanan, Southgate, and Smith's (2019) results who concluded that teachers need to be vigilant in what young people access online. The study reveals that teachers (Tonui, Kerich, \& Koross, 2016) lacked the necessary skills to deal with children's challenges in cyber abuse (Giménez-Gualdo et al., 2018). Consequently, the findings support the works of Kritzinger and Padayachee (2013), and Kuznekoff and Titsworth (2013) on the teacher's knowledge and skills of online challenges.

Subsequently, the study shows that teens do not trust teachers, so they cannot know what they experience online. Further, it reveals that teens access pornographic material accidental hence they access obscene material because there is inadequate guidance. Teachers face challenges in dealing with teens experiencing puberty. In contrast, the same teachers play a significant role in shaping adolescents' online safety behavior. Scholars such as Chou and Sun (2017) and Peter, Valkenburg, and Schouten (2006) concur with this argument. However, they feel that they are intruding into the privacy of young people.

The findings show that there are inadequate relevant online safety policies, structures to deal with cyberbullies, and curriculum vital to support the teachers in safeguarding them online. Lack of such systems impeded the capacity of teachers to oversee their learners in online platforms. Therefore, this study supports the finding Eden, Heiman, and Olenik-Shemesh (2013) and Giménez-Gualdo et al. (2018) that schools should develop intervention strategies to keep teens safe online.

\section{CONCLUSION}

It is evident from the findings of this study that teachers play a significant role in safeguarding teens online. On the other hand, technology is bringing a new challenge in the ever-changing society. The teachers face this new challenge since they are not competent enough to address them. They depend on the very young people they are supposed to protect to teach them to navigate digital platforms. Therefore, their hands are tied in safeguarding young people online. It is imperative to integrate online insecurity in the Kenya curriculum and schools to develop workable frameworks to support learners who have encountered troubles on the Internet.

Besides, teachers as the second "parents" to young people, can use their position to mediate their online activities. Therefore, they should be fully acquainted with the necessary competencies. Although the study was conducted in Kenya, some of its results may not be generalized since it is still developing technologically. While the study utilized a small sample, scholars Flyvbjerg (2006) have argued that such size has a limited effect and cannot invalidate such research findings. 
The study recommends effective digital literacy instruction intervention for teachers to support the teens in the online space effectively. Additionally, in-depth research exploring parents' responses to online challenges while protecting teens is a gap that needs to be filled. Lastly, this study focused on the teachers of teens of ages 12-14 years who have reported online insecurity. Exploring other young people of different ages who have not registered online insecurities can offer general stakeholders a great incite.

\section{REFERENCES}

Asher, D. O. (2014). Online Child Safety Case for Kenya (Briefing Paper No. 1 ; p. 5). CUTS International.

Bose, A., \& Coccaro, R. (2013). Understanding Africa Children's use of Information communication technologies (ICTs): A youth-led survey to prevent sexual exploitation online (p. 80) [Research]. ECPAT International.

Braun, V., \& Clarke, V. (2013). Successful Qualitative Research: A Practical Guide for Beginners. SAGE.

Buchanan, R., Southgate, E., \& Smith, S. P. (2019a). 'The whole world's watching really': Parental and educator perspectives on managing children's digital lives. Global Studies of Childhood, 9(2), 167-180. https://doi.org/10.1177/2043610619846351

Buchanan, R., Southgate, E., \& Smith, S. P. (2019b). 'The whole world's watching really': Parental and educator perspectives on managing children's digital lives. Global Studies of Childhood, 9(2), 167-180. https://doi.org/10.1177/2043610619846351

Byron, T. (2008). Safer Children in a Digital World The Report of the Byron Review. The Byron Review.

Chou, H.-L., \& Sun, J. C.-Y. (2017). The moderating roles of gender and social norms on the relationship between protection motivation and risky online behavior among in-service teachers. Computers $\mathcal{E}$ Education, 112, 83-96. https://doi.org/10.1016/j.compedu.2017.05. 003

Creswell, J. W. (2014). Research Design: Qualitative, Quantitative, and Mixed Methods Approaches. SAGE.

Cunha, F. R. da, van Kruistum, C., \& van Oers, B. (2016). Teachers and Facebook: Using online groups to improve students communication and engagement in education. Communication Teacher, 30(4), 228-241. https://doi.org/10.1080/17404622.2016. 1219039

Denzin, N., \& Lincoln, Y. (2005). The SAGE Handbook of Qualitative Research. SAGE.

Eden, S., Heiman, T., \& Olenik-Shemesh, D. (2013). Teachers' perceptions, beliefs and concerns about cyberbullying: Teachers' perceptions about cyberbullying. British Journal of Educational Technology, 44(6), 1036-1052. https://doi.org/10.1111/j.14678535.2012.01363.x

Flyvbjerg, B. (2006). Five Misunderstandings About Case-Study Research. Qualitative Inquiry, 12(2), 219-245. https://doi.org/10.1177/1077800405284363

Gill, S. (2013). A (Private) Public Space: Examining the Use and Impact of Digital and Social Media Among Adolescents in Kenya (p. 90). UNICEF.
Giménez-Gualdo, A.-M., Arnaiz-Sánchez, P., Cerezo-Ramírez, F., \& Prodócimo, E. (2018). Teachers' and students' perception about cyberbullying. Intervention strategies in Primary and Secondary education. Comunicar-Media Education Research Journal, XXVI(56), 29-38. https://doi.org/10.3916/C56-2018-03

Govender, I., \& Skea, B. (2015). Teachers' Understanding of E-Safety: An Exploratory Case in KZN South Africa. The Electronic Journal of Information Systems in Developing Countries, 70(1), 1-17. https://doi.org/10.1002/j.1681-4835.2015.tb00505.x

Hargie, O., \& Tourish, D. (2000). Handbook of Communication Audits for Organisations. Psychology Press.

Hartikainen, H., Iivari, N., \& Kinnula, M. (2019). Children’s design recommendations for online safety education. International Journal of Child-Computer Interaction, 22, 100146. https://doi.org/10.1016/j.ijcci.2019.100146

ICT Authority. (2014). The National ICT Masterplan towards a digital Kenya. Ministry of Information Communications and Technology.

IWS. (2020). Africa Internet Users, 2020 Population, and Facebook Statistics. https://www.Internetworldstats.com/stats1.htm

Kachwanya, K., Muthoni, J., \& Khamadi, S. (2018). State of the Internet in Kenya Report 2017 (p. 33) [Research]. Bloggers Association of Kenya.

Kinyanjui, M. (2014). 'Kids on the tab': Kenya National Library Service's Tablet Computers Project for slum school children. IFLA, 2014, Lyon. Retrieved from http://library.ifla.org/862/1/144-kinyanjui-en.pdf

Kritzinger, E., \& Padayachee, K. (2013). Engendering an e-safety awareness culture within the South African context. 2013 Africon, 1-5. https://doi.org/10.1109/AFRCON.2013.6757708

Kuznekoff, J. H., \& Titsworth, S. (2013). The Impact of Mobile Phone Usage on Student Learning. Communication Education, 62(3), 233252. https://doi.org/10.1080/03634523.2013.767917

Lee, N. M. (2018). Fake news, phishing, and fraud: A call for research on digital media literacy education beyond the classroom. Communication Education, 67(4), 460-466. https://doi.org/10.1080/ 03634523.2018.1503313

Lindlof, T. R., \& Taylor, B. C. (2002). Qualitative Communication Research Methods.

Lodico, M. G., Spaulding, D. T., \& Voegtle, K. H. (2010). Methods in Educational Research: From Theory to Practice (2nd ed.). Jossey-Bass.

Malby, S., Jesrani, T., Bañuelos, T., Holterhof, A., \& Hahn, M. (2015). Study on the Effects of New Information Technologies on the Abuse and Exploitation of Children. United Nations.

Muigai, N., \& Mantz, S. (2019). Global Mobile Consumer Survey The Kenyan Cut (p. 36). Deloitte.

Peter, J., Valkenburg, P. M., \& Schouten, A. P. (2006). Characteristics and Motives of Adolescents Talking with Strangers on the Internet. Cyberpsychology \& Behavior, 9(5), 526-530.

Polit, D. F., \& Beck, C. T. (2004). Nursing Research:Principles and Methods (7th ed.). Lippincott Williams \& Wilkins.

Ringrose, J., Gill, R., Livingstone, S., \& Harvey, L. (2012). A qualitative study of children, young people, and 'sexting': A report prepared for the NSPCC (pp. 1-77). National Society for the Prevention of Cruelty to Children. 
Saunders, M., Lewis, P., \& Thornhill, A. (2009). Research Methods for Business Students. Pearson Education.

Tonui, B., Kerich, E., \& Koross, R. (2016). An Investigation into Implementation of ICT in Primary Schools, in Kenya, in the Light of Free Laptops at Primary One A Case Study of Teachers Implementing ICT into Their Teaching Practice. Journal of Education and Practice, 7(13), 12-16.
UNICEF (Ed.). (2017). Children in a digital world. UNICEF.

Waller, M. (2017). The Role of Schools in Children's Online Safety. In J. Brown (Ed.), Online Risk to Children (pp. 217-230). John Wiley \& Sons, Ltd. https://doi.org/10.1002/9781118977545.ch12 